\title{
Comparison of Upper Extremity Physical Fitness Levels in Wheelchair Archery and Basketball Athletes
}

\author{
Ayşe Büşra ERTEN ${ }^{* 1}$, Gülay Aras BAYRAM ${ }^{2}$ iD and Zeliha Candan ALGUN ${ }^{3}$ iD
}

${ }^{1}$ Istanbul Medipol University, Institute of Health Sciences, Phsiotherapy and Rehabilitation Department, Istanbul, Turkey

${ }^{2}$ Istanbul Medipol University, Faculty of Health Sciences, Department of Phsiotherapy and Rehabilitation, Istanbul, Turkey

${ }^{3}$ Istanbul Medipol University, Faculty of Health Sciences, Department of Phsiotherapy and Rehabilitation, Istanbul, Turkey

*Corresponding author: abertenn@gmail.com

\begin{abstract}
Purpose: The aim of this study was to investigate the relationship between upper extremity physical fitness levels of wheelchair archery and wheelchair basketball athletes. Methods: Ten wheelchair basketball players and ten wheelchair archers, who met the inclusion criteria were included in the study. Athletes were divided into two groups according to their sports branch. Hand grip strength, shoulder flexibility, reaction time, trunk balance and upper extremity muscle strength were measured among the upper extremity physical fitness parameters. Measurements were repeated separately for both upper extremities. In addition, the demographic data of the individuals were recorded through the questionnaire. Results: There was no statistically significant difference between the groups in terms of age, height, weight and body mass index ( $p>0.05$ ). The years of disability and sports experience were significantly higher in basketball athletes, while weekly training hours were significantly higher in archery athletes $(\mathrm{p}<0.05)$. When the groups were compared, there was a statistically significant difference in right hand grip strength, trunk balance and all upper extremity muscle strength parameters in favor of wheelchair basketball athletes $(\mathrm{p}<0.05)$. There was no statistically significant difference in left hand grip strength, shoulder flexibility and reaction time of all upper extremities between the two groups $(\mathrm{p}>0.05)$. Conclusion: According to results, it was thought that these differences between two different sports groups are due to the different nature of the two sports branches and the fact that individuals cannot be distributed homogenously between groups according to the types of disabilities.
\end{abstract}

\section{Keywords}

Physical Fitness, Paralympic, Archery, Wheelchair, Basketball

\section{INTRODUCTION}

"The concept of disability involves individuals with long-term physical, mental, intellectual or perceptional disorders that prevent them from taking part in the society, under equal conditions with others in a complete and effective way" (Bickenbach et al., 1999). There are many sports activities that individuals with disabilities can perform with a wheelchair. Among these, wheelchair basketball is the first that comes to mind. On the other hand, wheelchair archery has become preferable more recently. Basketball, by its nature, is a fast and exciting sport requiring speed, whereas archery is more stationary and requires attention and focus, rather than speed. Wheelchair basketball is a team sport, whereas wheelchair archery can be performed both as an individual and team sport. Despite their differences, both are popular sports frequently preferred by individuals with disability (Gil-Agudo et al., 2010; Kim et al., 2018).

According to World Health Organization, physical fitness is defined as "social, mental and physical well-being" (Thompson et al., 2010). 
Some of the physical fitness parameters involve muscle strength, shoulder flexibility, body balance, reaction time etc. Due to both physical inactivity and certain physiological reasons, the level of physical fitness among individuals with disabilities is generally low. This has a negative impact on the functions of these individuals (Thompson et al., 2010).

Specific training and rehabilitation programs designed for the sports performed by individuals with disabilities have an impact on their level of success. In addition, in order to protect these individuals from secondary problems that may arise because of their disability, their level of physical fitness should also be evaluated and increased. While many studies in individuals with disabilities demonstrating the positive outcomes of performing a sport are available in the literature, whether performing a different sport will have different physical and psychological effects for the same disability level individuals are not known (Ambrose and Golightly, 2015; Barry et al., 2011; Frøsig and Richter, 2009; Loef and Walach, 2012; Uchida et al., 2012). For this reason, our study aimed to compare wheelchair basketball and wheelchair archery athletes with regard to their upper extremity physical fitness levels and examine the way different branches of sports impact individuals with physical disability.

\section{MATERIALS AND METHODS}

\section{Participants}

The study was conducted with the participation of the wheelchair basketball team's premier league athletes and paralympic archers from Istanbul Bağcılar Municipality Disability Sports Club and the paralympic archers of Istanbul Okçular Foundation Sports Club. The measurements were taken between the dates 20-29 April, 2019 at the Bağcılar Municipality's Göztepe Sports Complex and Okçular Foundation Sports Club, where the athletes attend for their regular training sessions. The participants were provided detailed information about the study and the individuals signed the written informed consent forms. The study protocol was reviewed by the local research ethics committee of Istanbul Medipol University at its meeting on March $29^{\text {th }}$, 2019 and was approved under the dossier number 10840098-604.01.01-E.12558. Ten wheelchair basketball players and ten wheelchair archers, regardless of their gender, were included in the study. Participants were required to be willing to take part in the study, literate, participating in the training sessions regularly for at least 1 year, with no history of upper extremity surgery in the last year, and with no existing mental problems preventing communication. One basketball player and one archer who suffered from an upper extremity injury and were unable to complete measurements were excluded from the study. The study was completed with the participation of 18 athletes. Participants were divided into two groups in accordance with their preferred sport activity.

\section{Measurements}

Demographics of all participants were recorded, followed by upper extremity measurement procedures. All measurements, with the exception of reaction time, were made three times for each extremity and the mean values were recorded. Hand grip strength was measured by Jamar (5030J1, Jamar, Sammons Preston, Inc, UK) hydraulic grip dynamometer. The measurements were made by using the second grip position of the device, which contains a total of five positions (Gerodimos, 2012). Shoulder flexibility was evaluated with the 'Back Scratch Test' (Dewhurst and Bampouras, 2014). Reaction time was evaluated by using the 'Nelson Visual Hand Reaction Test'. The measurements were taken for 20 times; the highest and the lowest 5 values were excluded and the mean of the remaining values were estimated (Oxendine, 1982). The strength of shoulder flexor, extensor, abductor, internal and external rotator muscles and elbow flexor muscles were measured with a Lafayette (Pelican 1150 Case, Pelican Products, Torrance, CA USA) myometer device (Livingston et al., 2015). Modified Functional Reach Test for evaluating the trunk balance was applied in 3 different versions including unilateral, bilateral and lateral reach (Magnani et al., 2017).

\section{Statistical Analysis}

Statistical analysis was performed by using the SPSS 18.0 (PASW 18, SPSS Inc, Chicago, USA) software. Data were expressed in terms of mean and standard deviation. Variables measured as numeric values were tested for normal distribution using the Shapiro-Wilks test. Since it was observed that the data were not normally distributed, statistical analysis was performed using the non-parametric Mann-Whitney U test. The statistical level of significance was accepted as $\mathrm{p}<0.05$. 


\section{RESULTS}

No significant difference was found between the groups with regard to age, height, weight and body mass index values ( $p>0.05)$, (Table 1$)$.
Years of sports experience and years of disability were found to be significantly higher in the basketball group, whereas weekly training time was significantly higher in the archery group $(\mathrm{p}<0.05)$, (Table 1).

Table 1. Comparison of the demographic features of athletes

\begin{tabular}{lccccc}
\hline Demographic Features & \multicolumn{2}{c}{$\begin{array}{c}\text { Archery } \\
\mathrm{n}=9\end{array}$} & \multicolumn{4}{c}{$\begin{array}{c}\text { Basketball } \\
\mathrm{n}=9\end{array}$} \\
\hline Bilateral Ampute & $\mathrm{n}$ & $\%$ & $\mathrm{n}$ & $\%$ & \\
Unilateral Ampute & 0 & 0 & 3 & 33.3 & \\
Polio & 0 & 0 & 2 & 22.2 & \\
Paraplegia & 0 & 0 & 2 & 22.2 & \\
Tetraplegia & 4 & 44.4 & 2 & 22.2 & \\
Spina Bifida & 3 & 33.3 & 0 & 0 & \\
\hline & 2 & 22.2 & 0 & 0 & $\mathbf{p}$ \\
Age (year) & Mean & SD & Mean & SD & 0.287 \\
Weight (kg) & 30.44 & 4.06 & 34.67 & 7.73 & 0.658 \\
Height (cm) & 71.33 & 11.44 & 74.11 & 12.61 & 0.250 \\
BMI (kg/m ${ }^{2}$ ) & 178.33 & 8.99 & 173.33 & 6.84 & 0.289 \\
Years of Sports Experience & 22.48 & 3.23 & 24.68 & 3.87 & $\mathbf{0 . 0 0 2}$ \\
Years of Disability & 4.22 & 4.06 & 14.11 & 5.18 & $\mathbf{0 . 0 3} *$ \\
Weekly Training Time & 15.44 & 8.11 & 27.00 & 9.17 & $\mathbf{0 . 0 0 0 *}$ \\
\hline
\end{tabular}

*Mann Whitney U Test, $\mathrm{p}<0.05 *$, sd: standard deviation

When athletes were compared with regard to their hand grip strength, no statistical difference was found between the groups with regard to right hand grip strength $(p>0.05)$, whereas a significant difference was detected in the left hand grip strength in favor of the basketball players $(\mathrm{p}<0.05)$, (Table 2). No significant difference was found between the groups upon the comparison of shoulder flexibility and reaction time ( $\mathrm{p}>0.05)$, (Table 2$)$.

Comparison of the functional reach test data between the groups revealed no significant difference for the findings of the bilateral reach test $(\mathrm{p}>0.05)$. However, a significant difference in favor of basketball players was observed for unilateral reach and lateral reach test findings $(p<0.05)$, (Table 2$)$.

Table 2. Comparison of athletes hand grip strength, shoulder flexibility, reaction time and trunk balance data

\begin{tabular}{|c|c|c|c|c|c|}
\hline & \multicolumn{2}{|c|}{$\begin{array}{c}\text { Archery } \\
n=9\end{array}$} & \multicolumn{2}{|c|}{$\begin{array}{c}\text { Basketball } \\
\mathbf{n}=9\end{array}$} & \multirow[b]{2}{*}{$\mathbf{p}$} \\
\hline & Mean & SD & Mean & SD & \\
\hline \multirow[t]{2}{*}{ Hand Grip Strength } & $\underline{\text { R } 33.14}$ & 20.70 & 47.54 & 9.74 & $\underline{0.171}$ \\
\hline & L 28.74 & 21.37 & 48.29 & 8.07 & $0.030 *$ \\
\hline \multirow[t]{2}{*}{ Shoulder Flexibility } & $\underline{\mathbf{R} 7.96}$ & 7.50 & 14.78 & 11.89 & $\underline{0.185}$ \\
\hline & L 13.50 & 14.10 & 16.50 & 9.89 & 0.627 \\
\hline \multirow[t]{2}{*}{ Reaction Time } & $\underline{\mathbf{R} 0.13}$ & 0.04 & 0.14 & 0.02 & 0.354 \\
\hline & L 0.19 & 0.14 & 0.14 & 0.03 & 0.791 \\
\hline \multirow[t]{2}{*}{ Lateral Reach } & $\underline{\mathbf{R} 15.91}$ & 5.50 & 23.16 & 5.87 & $\underline{0.015 *}$ \\
\hline & L 15.21 & 5.79 & 24.22 & 9.19 & $0.021 *$ \\
\hline Unilateral Reach & 30.77 & 13.18 & 44.81 & 10.71 & $0.031 *$ \\
\hline Bilateral Reach & 24.79 & 19.42 & 34.07 & 14.79 & 0.251 \\
\hline
\end{tabular}

*Mann Whitney U Test, $\mathrm{p}<0.05 *$, sd: standard deviation, R: Right, L: Left 
Comparison of the upper extremity muscle strength measurements revealed a statistically significant difference for all values in favor of the wheelchair basketball players. $(\mathrm{p}<0.05)$, (Table 3$)$.

Table 3. Comparison of upper extremity muscle strength data of athletes

\begin{tabular}{|c|c|c|c|c|c|}
\hline \multirow{2}{*}{$\begin{array}{l}\text { Upper Extremity } \\
\text { Muscle Strength }\end{array}$} & \multicolumn{2}{|c|}{$\begin{array}{c}\text { Archery } \\
\mathbf{n}=9\end{array}$} & \multicolumn{2}{|c|}{$\begin{array}{c}\begin{array}{c}\text { Basketball } \\
\mathbf{n}=9\end{array} \\
0\end{array}$} & \multirow[b]{2}{*}{ p } \\
\hline & Mean & SD & Mean & SD & \\
\hline \multirow[t]{2}{*}{ Shoulder Flexor } & R 11.74 & 4.87 & 30.51 & 6.13 & \multirow[b]{2}{*}{0.000} \\
\hline & L 11.19 & 3.62 & 31.46 & 5.19 & \\
\hline \multirow[t]{2}{*}{ Shoulder Extensor } & R 12.71 & 3.84 & 25.39 & 5.07 & \multirow[b]{2}{*}{$0.000 *$} \\
\hline & L 11.61 & 3.42 & 26.01 & 5.51 & \\
\hline \multirow[t]{2}{*}{ Shoulder Abductor } & R 9.46 & 3.35 & 26.90 & 5.12 & \multirow[b]{2}{*}{$0.000 *$} \\
\hline & L 8.34 & 3.82 & 27.66 & 4.45 & \\
\hline \multirow{2}{*}{$\begin{array}{l}\text { Shoulder Internal } \\
\text { Rotator }\end{array}$} & R 12.06 & 4.50 & 24.57 & 5.59 & \multirow[b]{2}{*}{$0.000 *$} \\
\hline & L 12.48 & 4.46 & 23.13 & 4.00 & \\
\hline \multirow{2}{*}{$\begin{array}{l}\text { Shoulder External } \\
\text { Rotator }\end{array}$} & $\underline{\mathbf{R} 6.80}$ & 2.63 & 21.56 & 3.29 & \multirow[b]{2}{*}{$0.000 *$} \\
\hline & L 7.00 & 3.26 & 21.17 & 3.81 & \\
\hline \multirow[t]{2}{*}{ Elbow Flexor } & R 15.01 & 4.61 & 31.84 & 5.40 & \multirow[b]{2}{*}{$0.000 *$} \\
\hline & L 12.89 & 5.78 & 31.83 & 4.53 & \\
\hline
\end{tabular}

*Mann Whitney U Test, $\mathrm{p}<0.05^{*}$, sd: standard deviation, R: Right, L: Left

\section{DISCUSSION}

Although there are various studies evaluating the physical fitness of the upper extremity in wheelchair basketball players in the literature, we could not come across any study that examining the physical fitness of the upper extremity in paralympic archery athletes. Therefore, our study was conducted in order to compare wheelchair basketball and archery athletes with regard to their upper extremity physical fitness levels.

While no difference was found between the archers and the basketball players with regard to right hand grip strength, a significant difference was observed for the left hand grip strength in favor of the basketball players. We think this difference is due to the rather low left hand grip strength of 3 athletes diagnosed with tetraplegia in the archery group. In a study by Gil et al., the dominant hand grip strength of 13 wheelchair basketball players included in the study was reported to be $44.96 \pm 9.98 \mathrm{~kg}$ (Gil et al., 2015). Yanci et al., reported a dominant hand grip strength of $44.50 \pm 11.33 \mathrm{~kg}$ for 16 wheelchair basketball players, as measured by Jamar hand dynamometer (Yanci et al., 2015). The results reported in the literature are observed to be similar to those obtained in our study (Gil et al., 2015; Wang et al., 2005; Yanci et al., 2015).

The period of time between the starting of the stimulus and the initiation of the reaction is defined as the reaction time (Gautam and Bade, 2017). In certain sports that particularly require speed, an athlete's fast response shortens the reaction time, and this in turn leads to a successful sports performance. Since basketball, by its nature, requires speed and agility, basketball players were expected to have better reaction times in comparison to archers in the study group. However, no significant difference was found between the two groups with regard to the reaction times for both hands. Wang et al., reported a simple visual reaction time of $0.19 \pm 0.02$ seconds for the dominant extremities of 37 wheelchair basketball players (Wang et al., 2005). Darilgen et al., divided the study group into two, based on their classification scores and evaluated the dominant extremity's reaction time with a Newtest reaction time meter. The visual reaction time of the participants were found to be $0.20 \pm 0.02$ seconds in both low and high degree trunk control groups. No significant difference was detected between the visual reaction times of the two groups (Darilgen and Yildirim, 2008). The reaction times of the athletes in our study are consistent with those 
reported in other published studies in the literature (Cömert et al., 2010; Darilgen and Y1ldırım, 2008; Wang et al., 2005).

Sitting balance is defined as the ability of the individual to control movement while leaning forward without any external support. Proximal stabilization and trunk balance are highly important, particularly for ensuring the regularity of the distal movement in individuals performing wheelchair sports (Gagnon et al., 2016; Santos et al., 2014). When the trunk balance of the athletes in our study were compared, basketball players were found to have better results than the archers. Trunk muscles, such as rectus abdominus, are innervated by the nerves at the T5-T12 levels of the spinal cord. Individuals with a spinal cord injury above these levels cannot maintain their trunk balance (Adegoke, 2002). The basketball group in our study included 2 paraplegic individuals with lesions at the T5 and T7 levels, whereas the archery group included 3 tetraplegic individuals with lesions at the C7-C8 levels and 4 paraplegic athletes with lesions at the T5-T12 levels. We think the difference observed between the groups with regard to trunk balance may be both due to the higher number of individuals with spinal cord injury and the higher level of spinal cord lesions in the archery group.

In a study by Ozunlu et al., trunk balance of 69 wheelchair basketball players were evaluated with the modified functional reach test (Ozunlu and Ergun, 2012). Among the athletes with three different types of disability, unilateral and lateral reach tests revealed no statistically significant difference, whereas a significant difference was found for the bilateral reach test findings. This study differs from ours in that regard. Ozunlu et al. reported that the 3 individuals with spinal cord injury in their study had paraparesis (Ozunlu and Ergun, 2012). On the other hand, our study included individuals with tetraplegia. Therefore, we think the difference between the trunk balance findings can be attributed to the fact that athletes in the two studies had different types of disability.

Most athletes usually perform exercises aimed to develop resistance, endurance and build muscle, whereas flexibility exercises are mostly neglected. However, a flexibility program implemented correctly may provide significant benefits. Although the wheelchair archery athletes in our study had greater shoulder flexibility in comparison to the basketball players, the difference was not statistically significant. Ergun et al., divided 32 wheelchair basketball players in accordance with their years of sports experience (Ergun et al., 2008). The first group with an experience of $2.5 \pm 1.5$ years had a shoulder flexibility of $13 \pm 8 \mathrm{~cm}$ and the second group had $4.5 \pm 4.5$ years of experience with a shoulder flexibility of $18 \pm 7 \mathrm{~cm}$, whereas the third group had $7.5 \pm 3$ years of experience and a shoulder flexibility of $16 \pm 7 \mathrm{~cm}$ (Ergun et al., 2008). In this regard, this study's findings are line with those observed in our study.

When the upper extremity muscle strength measurements of the athletes were compared, a significant difference in all parameters in favor of wheelchair basketball players was found. Wheelchair archery involves drawing the bow and shooting the arrow while sitting in a stationary position in the chair. Wheelchair basketball, by comparison, involves movement patterns that require active and fast utilization of the upper extremity, such as shooting, passing and dribbling the ball and retrieving rebounds. In addition to performing these patterns, the player has to use his upper extremities actively in order to move his wheelchair continuously in the playing field. Therefore, we think the difference between the two groups is the result of the different natures of the two sports involved in the study and we believe the fact that basketball players had a higher level of sports experience also contributed to this result.

Wang et al. reported the following results for the dominant upper extremity muscle strength of 37 basketball players, as evaluated by MP DA100B BioPac force measurement system: Shoulder flexion, $25.34 \mathrm{~kg}$; shoulder extension, $20.13 \mathrm{~kg}$; shoulder abduction, $23.72 \mathrm{~kg}$; and elbow flexion, $24.29 \mathrm{~kg}$ (Wang et al., 2005). Darilgen et al. used a dynamometer to measure the upper extremity muscle strength of 60 wheelchair basketball players divided into two, as low degree and high degree trunk control groups based on their classification scores. Muscle strength values of the high degree trunk control group were reported to be significantly higher than those in the low degree trunk control group (Darilgen and Y1ldırım, 2008). Our findings support those reported by Wang et al. and Darilgen et al. (Darilgen and Yildırım, 2008; Wang et al., 2005). Even though our values are similar, the fact that they are higher than those reported in the previous studies may be due to the relatively higher level of 
experience of the basketball players included in our study.

The findings in our study revealed a significant difference for muscle strength in the upper extremity, grip strength and trunk balance in favor of the wheelchair basketball players. We think that the difference in the grip strength and trunk balance in favor of basketballers is due to the individuals diagnosed with tetraplegia in the archery group. Although a significant difference in favor of basketball players could be expected for the reaction time and shoulder flexibility, no differences were observed between the groups. It is surprising that there is no difference in flexibility and reaction time among the athletes of these two sports branches, one of which is reguiring speed and the other one is more stable. However this may be owing to the low number of athletes in our study. That being said, while wheelchair basketball is the most popular sport among the paralympic sport activities, paralympic archery has only started to gain popularity recently. Especially in our country, the number of disabled individuals participating in this sport is very low compared to the basketball branch. Therefore, our study includes some limitations arising from the inadequate number of individuals performing archery. In time, as more people become interested in and perform this sport, we believe the study can be repeated with a higher number of participants in the future.

\section{REFERENCES}

Adegoke, B.O.A., Ogwumike, O.O., \& Olatemiju, A. (2002). Dynamic balance and level of lesion in spinal cord injured patients. African journal of medicine and medical sciences, 31(4), 357-360.

Ambrose, K.R., \& Golightly, Y.M. (2015). Physical exercise as non-pharmacological treatment of chronic pain: why and when. Best practice \& research Clinical rheumatology, 29(1), 120-130.

Barry, D.W., Hansen, K.C., Van Pelt, R.E., Witten, M., Wolfe, P., \& Kohrt, W.M. (2011). Acute calcium ingestion attenuates exercise-induced disruption of calcium homeostasis. Medicine and science in sports and exercise, 43(4), 617.

Bickenbach, J.E., Chatterji, S., Badley, E.M., \& Üstün, T.B. (1999). Models of disablement, universalism and the international classification of impairments, disabilities and handicaps. Social science \& medicine, 48(9), 1173-1187.

Cömert, E., Ün Yıldırım, N., \& Ergun, N. (2010). Tekerlekli sandalye basketbol oyuncularında üst ekstremite fonksiyonlarının değerlendirilmesi. Türkiye Klinikleri $J$ Sports, 62-69.

Darilgen, A., \& Yıldırım, N. Ü. (2008). Tekerlekli sandalye basketbol oyuncularında fiziksel uygunluğun değerlendirilmesi. Fizyoterapi Rehabilitasyon, 19(2), 64-73.

Dewhurst, S., \& Bampouras, T. M. (2014). Intraday reliability and sensitivity of four functional ability tests in older women. American journal of physical medicine \& rehabilitation, 93(8), 703-707.

Ergun, N., Düzgün, İ., \& Aslan, E. (2008). Effect of the number of years of experience on physical fitness, sports skills and quality of life in wheelchair basketball players. Turkish Journal of Physiotherapy and Rehabilitation, 19(2), 55-63.

Frøsig, C., \& Richter, E.A. (2009). Improved insulin sensitivity after exercise: focus on insulin signaling. Obesity, 17(S3), S15-S20.

Gagnon, D.H., Roy, A., Gabison, S., Duclos, C., Verrier, M. C., \& Nadeau, S. (2016). Effects of seated postural stability and trunk and upper extremity strength on performance during manual wheelchair propulsion tests in individuals with spinal cord injury: an exploratory study. Rehabilitation research and practice, 2016.

Gautam, Y., \& Bade, M. (2017). Effect of auditory interference on visual simple reaction time. Kathmandu Univ. Med. J. (KUMJ), 15(60), 329-331.

Gerodimos, V. (2012). Reliability of handgrip strength test in basketball players. Journal of human kinetics, 31(1), 25-36.

Gil-Agudo, A., Del Ama-Espinosa, A., \& CrespoRuiz, B. (2010). Wheelchair basketball quantification. Physical medicine and rehabilitation clinics of North America, 21(1), 141.

Gil, S.M., Yanci, J., Otero, M., Olasagasti, J., Badiola, A., Bidaurrazaga-Letona, I., ... \& Granados, C. (2015). The functional classification and field test performance in 
wheelchair basketball players. Journal of Human Kinetics, 46(1), 219-230.

Kim, R.N., Lee, J.H., Hong, S.H., Jeon, J.H., \& Jeong, W.K. (2018). The Characteristics of Shoulder Muscles in Archery Athletes. Clinics in Shoulder and Elbow, 21(3), 145.

Livingston, T., Bernardi, D., \& Carroll, M. (2015). The Commander ${ }^{\mathrm{TM}}$ Muscle Tester User's Manual. JTECH Medical, USA, 1-19.

Loef, M., \& Walach, H. (2012). The combined effects of healthy lifestyle behaviors on all cause mortality: a systematic review and meta-analysis. Preventive medicine, 55(3), 163-170.

Magnani, P.E., Cliquet Junior, A., \& Abreu, D.C. C.D. (2017). Postural control assessment in physically active and sedentary individuals with paraplegia. Acta ortopedica brasileira, 25(4), 147-150.

Oxendine, B. (1982). Psychology of motor learning II. New York: Mayfield Publications, 1, 270-295.

Ozunlu, N., \& Ergun, N. (2012). Trunk balance assessment in wheelchair basketball players. Turkish Journal of Physiotherapy and Rehabilitation, 23, 44-50.

Santos, S.D.S., Monteiro, C.B.D.M., Cantelli, B., Alonso, A. C., Mochizuki, L., Ré, A.H.N., \& Greve, J.M.D.A. (2014). Analysis of velocity and direction of trunk movement in wheelchair basketball athletes. MedicalExpress, 1(2), 77-80.

Thompson, W.R., Gordon, N.F., \& Pescatello, L. S. (2010). ACSM's guidelines for exercise testing and prescription. Wolters Kluwer Health/Lippincott Williams \& Wilkins.

Uchida, S., Shioda, K., Morita, Y., Kubota, C., Ganeko, M., \& Takeda, N. (2012). Exercise effects on sleep physiology. Frontiers in neurology, 3, 48.

Wang, Y.T., Chen, S., Limroongreungrat, W., \& Change, L.S. (2005). Contributions of selected fundamental factors to wheelchair basketball performance. Med Sci Sports Exerc, 37(1), 130-7.

Yanci, J., Granados, C., Otero, M., Badiola, A., Olasagasti, J., Bidaurrazaga-Letona, I., ... \& Gil, S.M. (2015). Sprint, agility, strength and endurance capacity in wheelchair basketball players. Biology of Sport, 32(1), 71.

How to cite this article: Erten, A.B., Bayram, G.A., and Algun, Z.C. (2021). Comparison of Upper Extremity Physical Fitness Levels in Wheelchair Archery and Basketball Athletes. Int J Disabil Sports Health Sci;4(1):73-79. https://doi.org/10.33438/ijdshs.885201

(C)Author(s) 2021 by the authors. This work is distributed under https://creativecommons.org/licenses/by-sa/4.0/ 